08.2

\title{
Влияние параметров короткопериодной сверхрешетки InGaAs/InGaAlAs на эффективность фотолюминесценции
}

\author{
(C) С.С. Рочас ${ }^{1}$, И.И. Новиков ${ }^{1}$, А.Г. Гладышев ${ }^{1}$, Е.С. Колодезный ${ }^{1}$, А.В. Бабичев ${ }^{1}$, В.В. Андрюшкин ${ }^{1}$, \\ В.Н. Неведомский ${ }^{2}$, Д.В. Денисов ${ }^{3}$, Л.Я. Карачинский ${ }^{1}$, А.Ю. Егоров ${ }^{4}$, В.Е. Бугров ${ }^{1}$ \\ ${ }^{1}$ Университет ИтМО, Санкт-Петербург, Россия \\ ${ }^{2}$ Физико-технический институт им. А.Ф. Иоффе РАН, ЦКП „Материаловедение и диагностика в передовых технологиях“, \\ Санкт-Петербург, Россия \\ ${ }^{3}$ Санкт-Петербургский государственный электротехнический университет „ЛЭТИ “, Санкт-Петербург, Россия \\ ${ }^{4}$ ООО „Коннектор Оптикс“, Санкт-Петербург, Россия \\ E-mail: stanislav_rochas@itmo.ru
}

Поступило в Редакцию 11 июня 2020г.

В окончательной редакции 23 июля 2020 г.

Принято к публикации 4 августа 2020 г.

\begin{abstract}
Представлены результаты исследования гетероструктур на основе короткопериодных сверхрешеток $\mathrm{InGaAs} / \mathrm{InGaAlAs,} \mathrm{изготовленных} \mathrm{методом} \mathrm{молекулярно-пучковой} \mathrm{эпитаксии} \mathrm{на} \mathrm{подложке} \mathrm{InP} \mathrm{и} \mathrm{предназна-}$ ченных для использования в качестве активных областей для вертикально-излучающих лазеров спектрального диапазона $1.3 \mu \mathrm{m}$. Проведены исследования изготовленных гетероструктур методами фотолюминесценции и рентгеновской дифракции. Показано, что изменение отношения толщины квантовой ямы и барьерного слоя сверхрешетки позволяет управляемо смещать положение пика фотолюминесценции для достижения лазерной генерации на длине волны $1.3 \mu \mathrm{m}$, при этом эффективность фотолюминесценции практически не меняется.
\end{abstract}

Ключевые слова: вертикально-излучающий лазер, активная область, сверхрешетка, квантовая яма, молекулярно-пучковая эпитаксия.

DOI: 10.21883/PJTF.2020.22.50304.18421

Основной прогресс в области полупроводниковых лазеров был связан с модернизацией активной области приборов - среды, которая отвечает за усиление оптического излучения. Снижение порогового тока за счет снижения размерности активной среды приводило к падению величины максимального оптического усиления в гетероструктурах, и при больших плотностях тока в них наблюдалось насыщение усиления, что вело к невозможности лазерной генерации при условии превышения уровня оптических потерь значением насыщенного оптического усиления. Увеличение усиления за счет использования нескольких квантовых ям (КЯ) [1] либо нескольких рядов квантовых точек (КТ) [2] не всегда позволяло достичь лазерной генерации, в особенности в вертикально-излучающих лазерах (ВИЛ), где в отличие от лазеров полосковой конструкции, работающих на длинах волн $1.3 \mu \mathrm{m}$, снижена эффективность перекрытия области, усиливающей свет со стоячей световой волной, возникающей в резонаторе лазера.

Использование короткопериодной сверхрешетки в качестве активной области ВИЛ спектрального диапазона $1.3 \mu \mathrm{m}$ может служить эффективной альтернативой применению гетероструктур активной области с несколькими рядами КЯ или КТ [3]. В таких гетероструктурах активная область представляет собой повторяющиеся пары полупроводниковых слоев КЯ/барьер, выполненных из InGaAs/InGaAlAs, в которых усиление света осуществляется за счет инжекционной накачки и взаимодействия со стоячей световой волной короткопериодной сверхрешетки. В отличие от традиционных гетероструктур на основе КЯ и КТ в гетероструктурах с короткопериодной сверхрешеткой образуется минизона [4], расположенная как в области КЯ, так и в области барьерных слоев, благодаря чему ширина эффективной части активной области такой структуры в 2 раза выше, чем у структуры с КЯ, и составляет $20 \%$ длины волны генерируемого излучения за счет увеличения интеграла перекрытия стоячей световой волны с областью, усиливающей свет [3]. Кроме того, функция плотности состояний носителей заряда в таких структурах имеет вид, близкий к функции плотности состояний носителей заряда в гетероструктурах с КЯ, а значит, за счет повышения усиления можно добиться снижения порогового тока [5].

В настоящей работе были исследованы четыре гетероструктуры (№ 1-4) активных областей ВИЛ спектрального диапазона $1.3 \mu \mathrm{m}$ на основе короткопериодной сверхрешетки InGaAs/InGaAlAs, выращенные методом молекулярно-пучковой эпитаксии на установке Riber 49. В качестве подложки был использован InP (100). Со стороны подложки и поверхности сверхрешетка гетероструктур ограничена барьерными слоями $\operatorname{In}_{0.52} \mathrm{Al}_{0.48} \mathrm{As} / \mathrm{In}_{0.53} \mathrm{Ga}_{0.27} \mathrm{Al}_{0.2} \mathrm{As}$. Сверхрешетка представляет собой 25 пар чередующихся слоев КЯ/барьер $\mathrm{In}_{0.6} \mathrm{Ga}_{0.4} \mathrm{As} / \mathrm{In}_{0.53} \mathrm{Ga}_{0.27} \mathrm{Al}_{0.2} \mathrm{As}$ с разным от- 


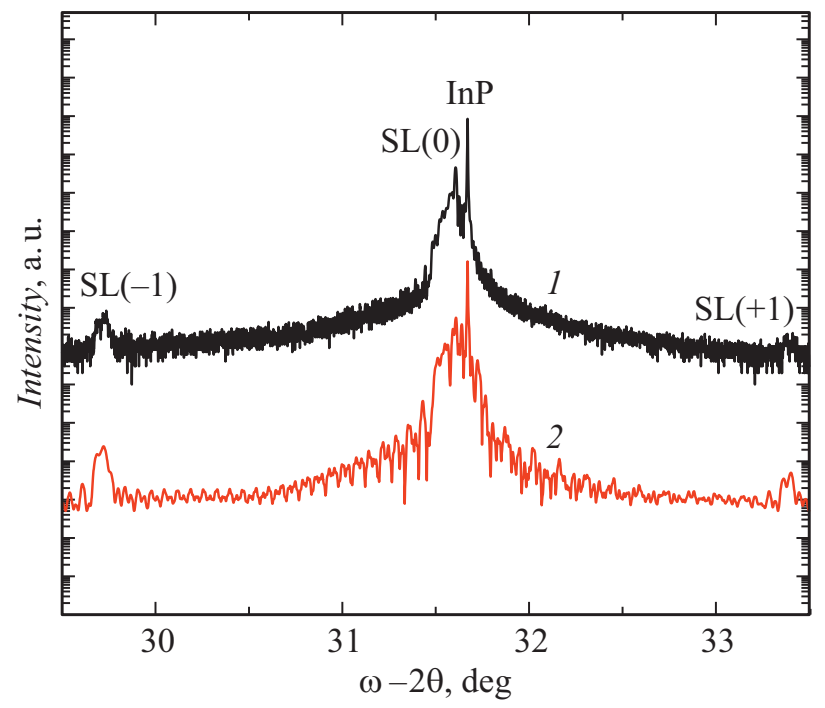

Рис. 1. Рентгенодифракционные кривые гетероструктуры № 1. 1 - экспериментальная кривая, 2 - модельная кривая.

ношением толщин чередующихся слоев для гетероструктур № $1-4$.

Реализация ВИЛ, полученных методом спекания [6], связана с необходимостью удаления подложки активной области перед процессом спекания гетероструктур. Как следствие, в конструкции гетероструктуры активной области требуется вставка стоп-слоя $\mathrm{In}_{0.53} \mathrm{Ga}_{0.47} \mathrm{As}$, отличающегося по составу от слоев $\mathrm{InGaAs}$, используемых в качестве слоев активной области. Реализация в одном ростовом процессе двух слоев InGaAs различного состава связана с изменением температуры источника индия на $27^{\circ} \mathrm{C}$. Для проверки влияния такого изменения температуры на параметры активной области в гетероструктурах № 3 и 4 перед осаждением сверхрешетки температура источника индия повышалась на $27^{\circ} \mathrm{C}$ для соответствия режимов роста будущим гетероструктурам активной области ВИЛ, включающим стоп-слой $\mathrm{In}_{0.53} \mathrm{Ga}_{0.47} \mathrm{As}$. Толщины слоев КЯ/барьер гетероструктуры № 1 составили 0.8 и $2 \mathrm{~nm}$ соответственно. Толщины слоев КЯ/барьер гетероструктуры № 2 и гетероструктуры № 3 составили 0.7 и $2.1 \mathrm{~nm}$. Толщины слоев яма/барьер гетероструктуры № 4 составили 0.6 и $2.2 \mathrm{~nm}$.

Исследование структурного качества гетероструктур осуществлялось методом рентгенодифракционного анализа с использованием дифрактометра PANalytical X'PertPro MRD в параллельной геометрии пучка рентгеновского излучения. В качестве источника излучения (мощностью $1.2 \mathrm{~kW}$ ) была использована трубка с медным анодом $(\lambda=0.15406 \mathrm{~nm})$. Полуширина первичного пучка не превышала $12^{\prime \prime}$, что обеспечивалось использованием четырехкратного $\mathrm{Ge}$ (220) прорезного кристалла-монохроматора. Спектры фотолюминесценции (ФЛ) измерялись при комнатной температуре на установке PM2000, VerteX, Nanometrics с применением InGaAs-фотодетектора и полупроводникового лазера с длиной волны $788 \mathrm{~nm}$, скорость измерений составляла 10 точек в секунду, размер щели $2 \mathrm{~mm}$, дифракционная решетка имела 300 lines/mm.

C помощью рентгенодифракционного анализа гетероструктур был определен состав слоев сверхрешетки. Экспериментальные и модельные рентгенодифракционные кривые для гетероструктуры № 1 приведены на рис. 1. Пик максимальной интенсивности на кривой качания соответствует подложке InP. Левее расположен пик дифракции, определяющий средний состав сверхрешетки $\mathrm{In}_{0.6} \mathrm{Ga}_{0.4} \mathrm{As} / \mathrm{In}_{0.53} \mathrm{Ga}_{0.27} \mathrm{Al}_{0.2} \mathrm{As}$, по бокам слева и справа от центрального пика находятся пикисателлиты сверхрешетки $\operatorname{In}_{0.6} \mathrm{Ga}_{0.4} \mathrm{As} / \mathrm{In}_{0.53} \mathrm{Ga}_{0.27} \mathrm{Al}_{0.2} \mathrm{As}$, средняя мольная доля индия в слоях сверхрешетки составила 0.57. Моделирование кривой качания позволило определить состав слоев сверхрешетки гетероструктуры № 1, который совпал с экспериментальными данными.
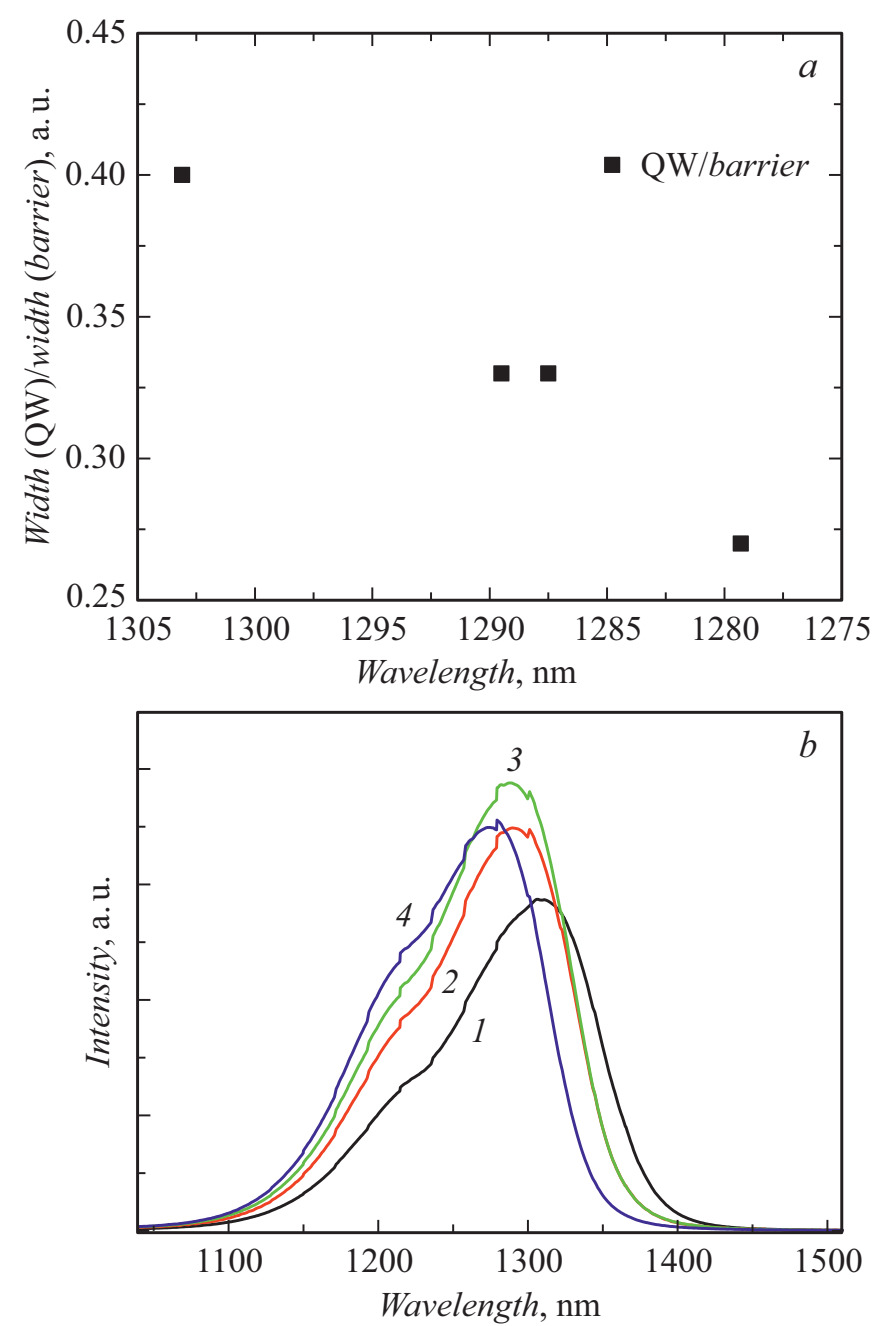

Рис. 2. Исследование ФЛ гетероструктур № 1-4. Длина волны накачного лазера $788 \mathrm{~nm}$ при мощности оптической накачки $45 \mathrm{~mW}$. $a$ - зависимость пиковой длины волны спектра ФЛ от отношения толщин слоев КЯ/барьер в слоях сверхрешетки; $b-$ спектры ФЛ гетероструктур № 1-4 (кривые 1-4 соответственно). 

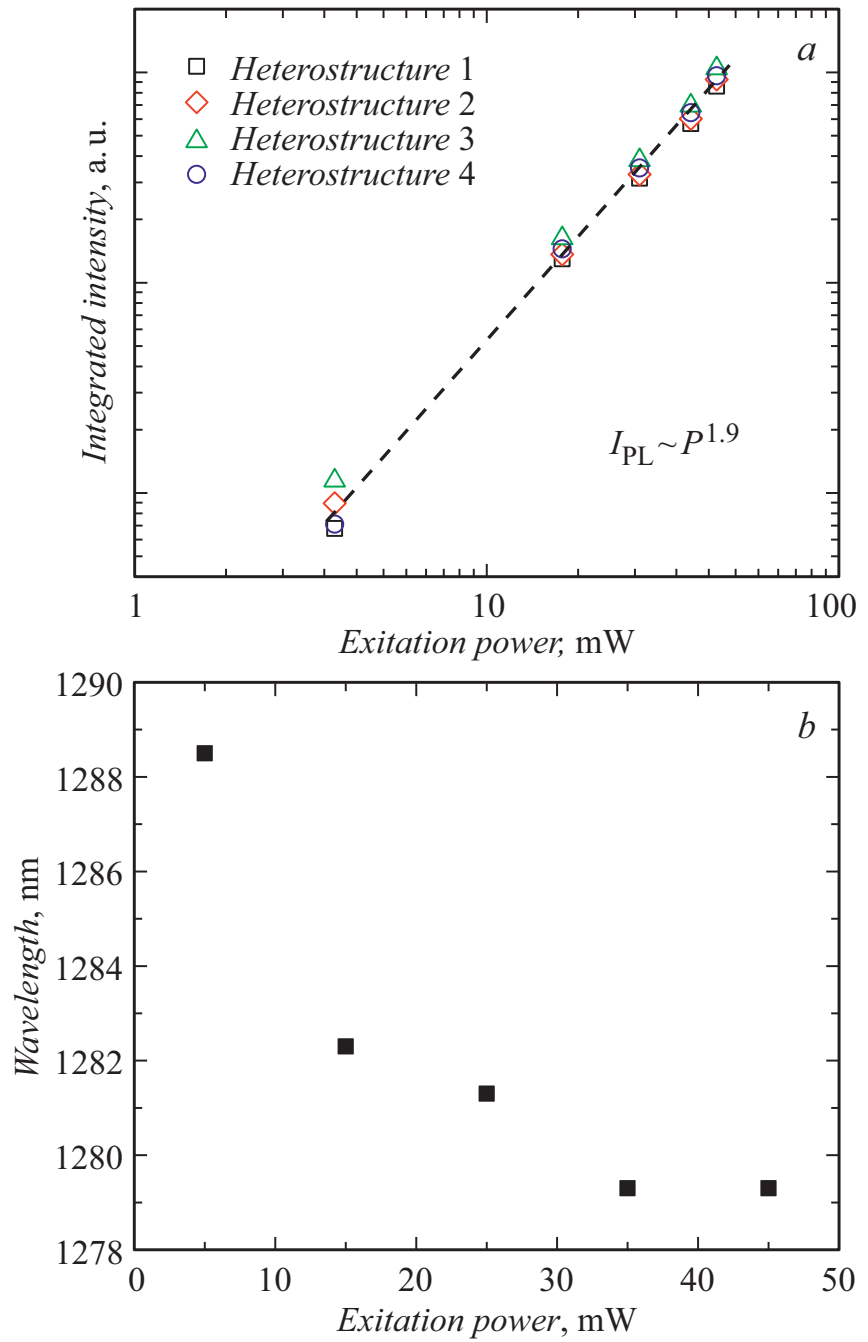

Рис. 3. Зависимость ФЛ гетероструктур от мощности накачки. Длина волны накачного лазера $788 \mathrm{~nm}$. $a-$ интегральная интенсивность ФЛ гетероструктур № 1-4 (Heterostructure $1-4)$ в зависимости от мощности оптической накачки (в полулогарифмическом масштабе); $b$ - зависимость пиковой длины волны ФЛ гетероструктуры № 4 от мощности оптической накачки.

Осуществлялось изменение толщин слоев сверхрешетки с целью достижения пика ФЛ исследуемой гетероструктуры на длинах волн $1280 \mathrm{~nm}$ (рис. 2, a), что при использовании сверхрешетки исследуемой гетероструктуры в качестве активной области ВИЛ будет оптимальным для получения лазерной генерации ВИЛ на длинах волн $1.3-1.31 \mu \mathrm{m}$ [7].

На рис. 2, $b$ представлены спектры ФЛ для четыpex гетероструктур при мощности оптической накачки, равной $45 \mathrm{~mW}$ (длина волны возбуждающего излучения $788 \mathrm{~nm}$ ). По мере уменьшения толщины КЯ и увеличения толщины барьера наблюдается смещение пика ФЛ в коротковолновую область спектра. Пики ФЛ находятся на длинах волн 1303.1, 1289.5, 1287.5, $1279.3 \mathrm{~nm}$ для гетероструктур № 1-4 соответственно.
Разница в интенсивности пика ФЛ гетероструктур № 2 и 3 при одинаковых толщинах КЯ/барьер объясняется тем, что из-за инертности источника индия его температура в выбранных ростовых режимах не успела достичь заданного значения, и поток индия оказался меньше запланированного, что привело к уменьшению состава слоя $\mathrm{In}_{0.6} \mathrm{Ga}_{0.4} \mathrm{As}$ сверхрешетки по индию.

Зависимость интегральной интенсивности ФЛ гетероструктур от мощности оптической накачки представлена на рис. 3, $a$. Показано, что с увеличением уровня накачки все гетероструктуры демонстрируют приблизительно равную интенсивность ФЛ, что свидетельствует об одинаковом оптическом качестве гетероструктур, выращенных при различной температуре. Полученные экспериментальные данные подчиняются степенному закону с показателем $\alpha \approx 1.9$, что свидетельствует о преимущественном механизме излучательной рекомбинации свободных носителей.

На рис. 3, $b$ представлена зависимость длины волны пика ФЛ гетероструктуры № 4 от мощности оптической накачки. Заполнение электронных состояний в зоне проводимости минизоны сверхрешетки, образованной за счет связывания волновых функций соседних КЯ через тонкие потенциальные барьеры, при росте уровня оптической накачки приводит к увеличению энергии оптического перехода, вследствие чего происходит смещение пика ФЛ в коротковолновую область с 1287.3 до $1279.3 \mathrm{~nm}$.

Таким образом, в работе представлены результаты исследования ФЛ четырех гетероструктур на основе короткопериодных сверхрешеток для активных областей ВИЛ спектрального диапазона $1.3 \mu \mathrm{m}$. Были определены состав и толщины слоев яма/барьер сверхрешетки $\mathrm{InGaAs} / \mathrm{InGaAlAs}$ для достижения лазерной генерации ВИЛ на длине волны $1.3 \mu \mathrm{m}$. Предложенная и реализованная гетероструктура № 4 продемонстрировала пик ФЛ на длине волны вблизи $1280 \mathrm{~nm}$ при мощности оптической накачки $45 \mathrm{~mW}$ без падения эффективности ФЛ (по сравнению с другими исследованными гетероструктурами), что в дальнейшем позволит реализовать ВИЛ на длинах волн $1.3-1.31 \mu \mathrm{m}$, изготовленные методом спекания [5].

\section{Финансирование работы}

Работа выполнена при поддержке Министерства науки и высшего образования РФ (проект тематики научных исследований № 2019-1442).

\section{Конфликт интересов}

Авторы заявляют, что у них нет конфликта интересов. 


\section{Список литературы}

[1] Megalini L., Bonef B., Cabinian B.C., Zhao H., Taylor A., Speck J.S., Bowers J.E., Klamkin J. // Appl. Phys. Lett. 2017. V. 111. N 3. P. 032105. DOI: $10.1063 / 1.4994318$

[2] Kim S.M., Wang Y., Keever M., Harris J.S. // IEEE Photon. Technol. Lett. 2004. V. 16. N 2. P. 377-379.

DOI: $10.1109 /$ LPT.2003.823088

[3] Карачинский Л.Я., Новиков И.И., Бабичев А.В., Гладышев А.Г., Колодезный Е.С., Рочас С.С., Курочкин А.С., Бобрецова Ю.К., Климов А.А., Денисов Д.В., Воропаев К.О., Ионов А.С., Бугров В.Е., Егоров А.Ю. // Оптика и спектроскопия. 2019. Т. 127. В. 6. С. 963-966.

DOI: $10.21883 /$ OS.2019.12.48693.124-19

[4] Renk K.F. Quantum cascade laser // Basics of laser physics. Cham: Springer, 2017. P. 545-551.

DOI: 10.1007/978-3-319-50651-7 29

[5] Babichev A.V., Karachinsky L.Ya., Novikov I.I., Gladyshev A.G., Blokhin S.A., Mikhailov S., Iakovlev V., Sirbu A., Stepniak G., Chorchos L., Turkiewicz J.P., Voropaev K.O., Ionov A.S., Agustin M.A., Ledentsov N.N., Egorov A.Yu. // IEEE J. Quant. Electron. 2017. V. 53. N 6. P. 1-8.

DOI: $10.1109 /$ JQE.2017.2752700

[6] Syrbu A., Mircea A., Mereuta A., Caliman A., Berseth C.-A., Suruceanu G., Iakovlev V., Achtenhagen M., Rudra A., Kapon E. // IEEE Photon. Technol. Lett. 2004. V. 16. N 5. P. 1230-1232. DOI: 10.1109/LPT.2004.826099

[7] Piprek J., Mehta M., Jayaraman V. Design and optimization of high-performance 1.3- $\mu \mathrm{m}$ VCSELs // Physics and simulation of optoelectronic devices XII. 2004. V. 5349. P. 375-384.

DOI: $10.1117 / 12.543062$ 